\title{
RELEVANSI KEARIFAN LOKAL TEPUNG TAWAR DALAM PEMBELAJARAN AGAMA ISLAM (STUDI PADA MASYARAKAT MELAYU PONTIANAK)
}

\author{
Dendy Ramadhan ${ }^{1 *}$ dan Wahab ${ }^{2}$ \\ ${ }^{1,2}$ Program Pascasarjana \\ Institut Agama Islam Negeri Pontianak \\ *Email: dendydendy503@gmail.com
}

Website : https://jurnal.uin-antasari.ac.id/index.php/jtjik/index

Received: Februari 2019; Accepted: Agustus 2019; Published: Agustus 2019

\begin{abstract}
This article discusses a custom of Pontianak Malay society, one of which is tepung tawar. Preservation of tradition must be maintained and can be passed on to the younger generation. Local wisdom refers to various cultural riches that grow and develop in a society that are known, trusted, and recognized as important elements that are able to strengthen social cohesion among community members and one of the ideas and ideas followed by a local community. Fresh flour is a series that is carried out when children's hair clippers, weddings, circumcisions, or establishing and moving houses. From here it can be linked to the learning of Islamic Religious Education (PAI). This study used a qualitative method with an ethnographic approach that narrated a Malay customary culture in the implementation of fresh flour such as body fresh flour, corpse flour, equipment flour. Research findings are to make a local wisdom based learning plan (RPP) in the learning of Islamic Religious Education (PAI). Regarding fresh flour is included in the preparation of learning devices and does not leave behind existing theories.
\end{abstract}

Keywords: tepung tawar; local wisdom; islamic religious education

\begin{abstract}
ABSTRAK
Artikel ini membahas mengenai suatu kebiasaan masyarakat Melayu Pontianak salah satunya tepung tawar. Preservasi tradisi harus dijaga serta dapat diwariskan pada generasi muda. Kearifan lokal mengacu pada berbagai kekayaan budaya yang tumbuh dan berkembang dalam sebuah masyarakat yang dikenal, dipercayai, dan diakui sebagai elemen-elemen penting yang mampu mempertebal kohesi sosial diantara warga masyarakat serta salah satu ide dan gagasan yang diikuti oleh suatu komunitas setempat. Tepung tawar merupakan suatu rangkaian yang dilaksanakan ketika gunting rambut anak, pernikahan, khitanan, maupun mendirikan dan pindah rumah. Dari sini bisa dikaitkan dengan pembelajaran Pendidikan Agama Islam (PAI). Penelitian ini menggunakan metode kualitatif dengan pendekatan etnografi yang menarasikan sebuah adat kebiasaan masyarakat melayu dalam pelaksanaan tepung tawar seperti tepung tawar badan, tepung tawar mayat, tepung tawar peralatan. Temuan Penelitian adalah membuat sebuah rencana pelaksanaan pembelajaran (RPP) berbasis kearifan lokal dalam pembelajaran Pendidikan Agama Islam (PAI). Mengenai tepung tawar dimasukkan dalam penyusunan perangkat pembelajaran dan tidak meninggalkan teori yang sudah ada.
\end{abstract}

Kata Kunci: tepung tawar; kearifan lokal; pembelajaran agama islam

\section{PENDAHULUAN}

Setiap daerah memiliki budaya maupun adat istiadat di masing-masing tempat yang bermacam-macam dan berbeda-beda mulai berbentuk dari tradisi, perilaku, syair, lagu, busana, alat musik tradisional dan lain sebagainya. Dari kesemuanya tersebut memiliki esensi dan filosofi yang begitu dalam sehingga 
memiliki suatu nilai yang bermakna baik secara simbolik maupun prosesi. Budaya merupakan bentuk dari sistem yang mempunyai koherensi dengan sistem yang lain. Bentuk-bentuk simbolis yang berupa kata, benda, laku, sastra, lukisan, nyanyian, musik, kepercayaan mempunyai kaitan erat dengan konsep-konsep epistemologi dari sistem pengetahuan masyarakat (Sri Astuti A. Samad, 2017: 28).

Kebudayaan merupakan elemen yang tidak bisa dilepaskan dari kehidupan manusia. Sebagai warisan nenek moyang, kebudayaan mampu membentuk kebiasaan dalam berkehidupan sehari-hari yang diwariskan secara turun-temurun (Abdul Basir, 2013:69). Oleh sebab itu, budaya merupakan bagian dari kearifan lokal yang harus dijaga serta dapat diwariskan pada generasi muda.

Kearifan lokal mengacu pada berbagai kekayaan budaya yang tumbuh dan berkembang dalam sebuah masyarakat yang dikenal, dipercayai, dan diakui sebagai elemen-elemen penting yang mampu mempertebal kohesi sosial diantara warga masyarakat (Masita, 2012:305). Sebagaimana menurut Zainuddin Maliki yang dikutip Wahab (2015: 253) di dalam jurnalnya yaitu sebagai berikut:

"The structural-functional theory belongs to Emile Durkheim. This theory sees people tend to move and lead to the creation of a social order that tends to maintain the status quo".

Kearifan lokal dapat dimasukkan dalam kurikulum pendidikan khususnya dalam pembelajaran Pendidikan Agama Islam yang berlandaskan pada Alquran maupun As-Sunah. Isi kearifan lokal itu dapat dimasukkan atau disisipkan dalam pembelajaran rumpun PAI seperti fiqih, Sejarah kebudayaan Islam (SKI), aqidah akhlak, al-Quran Hadist. Akan tetapi tidak mengubah esensi melalui judul besar dan sub judul yang sudah ada.

Perlunya kurikulum Pendidikan Agama Islam berbasis kearifan lokal ini yang berisikan suatu nilai-nilai karakter didalamnya adalah menjawab tantangan di masyarakat dikarenakan mulai menurun dan memudar terutama pada generasi-generasi milenial yang sibuk dengan penggunaan teknologi. Kebanyakan teknologi yang ada disalahgunakan seperti penggunaan media sosial yang bisa menyebarkan berita hoax maupun ujaran kebencian.

Tak terlepas juga Pendidikan Agama Islam yang ada di Kota Pontianak. Mayoritas penduduk Kota Pontianak adalah suku Melayu, beragama Islam dan memiliki ikon budaya adat kebiasaan. Salah satunya adat istiadat tepung tawar. Masyarakat melayu Pontianak memiliki tradisi tepung tawar yang termasuk dalam sistem kebudayaan religi. Pada prosesi tepung tawar adanya berdoa dan bershalawat pada Nabi Saw, diyakini membawa keselamatan dan menolak bala'.

Kajian budaya tepung tawar dapat dilihat secara sosial, ilmu pengetahuan, teknologi dan budaya. Secara sosial terjadi dengan adanya interaksi sosial pada masyarakat melalui tokoh-tokoh yang mempunyai pengaruh dan peran penting yang dianggap terpandang dalam masyarakat melayu Pontianak. Secara ilmu pengetahuan, bahwa tepung tawar memiliki cara-cara tersendiri dengan tahap-tahapnya seperti memercikan air pada orang atau benda dan lain-lain sebagainya. Secara teknologi, berkaitan dengan alat atau media yang digunakan tepung tawar. Secara bahasa, bahasa yang digunakan sehari-hari dan pengantar masyarakat Pontianak adalah melayu.

Hal ini sesuai dengan pernyataan Atem (2017) bahwa masyarakat selalu hadir dengan berbagai nilai, budaya, adat istiadat dan tradisi di dalamnya. Tidak salah bila dikatakan masyarakat dan budaya adalah saling timbal balik. Ada banyak bentuk budaya, adat dan tradisi yang dianut oleh setiap kelompok masyarakat di Indonesia, bahkan dalam rumpun yang sama etnis akan ditemukan perbedaan tradisi dan budaya didalamnya

Pembelajaran pendidikan agama Islam yang ada di sekolah umum maupun madrasah sebagai upaya untuk memperkuat 
serta menanamkan nilai-nilai karakter pada siswa dari mata pelajaran baik itu fiqih, SKI, al-Quran Hadis, dan aqidah akhlak. Maka itu guru pendidikan agama Islam sebagai pengajar dan pendidik memberikan sebuah pengajaran dengan berbagai metode, strategi, model serta pendekatan agar bisa dipahami dan juga diaplikasikan siswa dalam kehidupan sehari-hari. Adapun pembelajaran pendidikan agama Islam dapat diintegrasikan dengan budaya kearifan lokal yaitu tepung tawar masyarakat melayu Pontianak.

Kurikulum yang saat ini digunakan adalah kurikulum 2013, menitikberatkan pada aspek afektif. Oleh sebab itu, Kurikulum 2013 perlu digabungkan dengan kearifan lokal sehingga akan memberikan sebuah warna yaitu manusia berbudaya dan karakakter. Secara otomatis juga bisa berupa pelestarian nilai-nilai warisan budayabudaya nusantara.

Alasan pentingnya nilai karakter dalam perangkat pembelajaran diungkapkan Wahab (2013:105-106) bahwa pengintegrasian pendidikan karakter ke dalam semua materi pembelajaran dilakukan dalam rangka mengembangkan kegiatan intervensi pendidikan kemudian pendidikan karakter bukan sekedar mengajarkan mana yang benar dan mana yang salah. Akan tetapi, lebih dari itu, pendidikan karakter menanamkan kebiasaan (habituation) tentang hal mana yang baik sehingga peserta didik menjadi paham (kognitif) tentang mana yang benar dan salah, mampu merasakan (afektif) nilai yang baik dan biasa melakukannya (psikomotor).

Penyusunan materi tentang

Pendidikan Agama Islam harus mencakup materi pendidikan ketauhidan, fikih, ibadah, dan lain sebagainya, yang mengantarkan peserta didik menjadi manusia yang insan kamil beragama yang memahami ajaran agamanya dengan baik dan mampu mengaplikasikannya dalam kehidupan sehari-hari dengan terampil dan benar (Ade Imelda Frimayanti, 2017: 242).

Menurut Imam Santoso Ermawi dalam Aslan ( 2017:13) menjelaskan bahwa kearifan lokal Kearifan lokal adalah pikiran positif manusia yang berhubungan dengan alam, lingkungan yang bersumber dari adat istiadat, nilai agama, petuah-petitih nenek moyang yang terbentuk oleh masyarakat sekitar. Warisan ini dijadikan sebagai alat kontrol di masyarakat dan sudah melembaga sehingga menjadi kebudayaan.

Selanjutnya menurut Keraf dalam Sulma Mafirja dkk (2018: 104) menegaskan bahwa kearifan lokal adalah semua bentuk pengetahuan, keyakinan, pemahaman atau wawasan serta adat kebiasaan atau etika yang menuntun perilaku manusia dalam kehidupan di dalam komunitas ekologis. Sementara itu menurut Muhammad Priyatna (2016:1313) Kearifan lokal (local wisdom) dapat dipahami sebagai gagasan, nilai-nilai, pandangan-pandangan setempat (local) yang bersifat bijaksana, penuh kearifan, bernilai baik, yang tertanam dan diikuti oleh anggota masyarakatnya. Berdasarkan pendapat tersebut diatas bahwa kearifan lokal merupakan adat istiadat yang mempunyai nilai-nilai yang dapat memberikan wawasan dan gagasan kepada masyarakat agar beretika maupun bijaksana dalam menghadapi kehidupan disekitarmya.

Yusriadi (2017) menyatakan suatu bentuk budaya masyarakat dapat dianggap sebagai kearifan lokal jika memenuhi empat unsur: (1). Warisan, yaitu sesuatu yang diperoleh dari generasi sebelumnya, baik dari garis ayah, ibu atau paman dan orangorang yang satu generasi dengannya. (2). Hidup dalam ruang tertentu atau milik komunitas tertentu, yang bermakna bahwa pengetahuan ini diakui keberadaannya. (3) Budaya itu mengalami perubahan atau penyesuaian dengan lingkungan alam terkini. (4). Budaya itu bermanfaat atau mendatangkan kebaikan untuk hubungan manusia dengan lingkungannya.

Pemaparan tersebut yang melatarbelakangi peneliti untuk membahas serta mengkaji tentang tepung tawar yang dikaitkan dengan pembelajaran agama Islam. 


\section{METODE PENELITIAN}

Penelitian ini menggunakan metode kualitatif dengan pendekatan etnografi. Creswell menyebutkan bahwa etnografi ialah mengkaji dan mendiskripsikan suatu komunitas masyarakat yang memiliki kebudayaan sama baik dari bahasa, perilaku maupun keyakinan. Penelitian ini membahas mengenai tepung tawar masyarakat melayu Pontianak dilihat dari perilakunya. Teknik pengumpulan data yang digunakan adalah observasi, wawancara dan dokumentasi. Analisis data dengan mereduksi data-data yang sesuai dengan kebutuhan penelitian kemudian dideskripsikan sesuai dengan arah tujuan penelitian.

\section{HASIL DAN PEMBAHASAN}

Tepung tawar ialah salah satu adat istiadat yang dilakukan oleh masyarakat Melayu khususnya di Pontianak. Tepung tawar dibagi menjadi dua yaitu dilakukan pada acara yang diiringi seperti pernikahan, gunting rambut, khitanan, mendirikan rumah, serta pindah rumah. Sedangkan pada suatu barang atau peralatan yang dibeli seperti mobil, motor, sampan, umumnya kendaraan.

Pengumpulan data dengan cara wawancara tentang kepada pegawai Balai Kajian Pelestarian Budaya Pontianak Kalimantan Barat. Hasil wawancara menyebutkan bahwa epung tawar untuk acara maupun untuk benda atau barang yang dibeli memiliki prosesinya yang berbeda. Pelaksanaan tepung tawar untuk acara yaitu memercikan/dikibaskan air kepada orang yang mempunyai acara yang dilanjutkan dengan menaburi beras kuning dan berteh serta diiringi pembacaan shalawat Nabi Saw. Kemudian pelaksanaan tepung tawar untuk barang atau benda yaitu memercikan/dikibaskan air ke barang atau benda tersebut dengan sambil membaca ayat suci Alquran yakni doa selamat dan doa tolak bala'.

\begin{tabular}{|c|c|c|}
\hline \multicolumn{2}{|c|}{ Keyakinan } & masyarakat \\
\hline menepung & tawar & kendaraan \\
\hline kendaraan & yang & dipergunakan \\
\hline
\end{tabular}

mendatangkan musibah. Hal ini disebabkan karena kendaraan tersebut mempergunakan bahan-bahan yang terbuat dari besi yang biasa disebut dengan tua besi. Besi bisa membawa tuah keberuntungan dan juga bisa membawa kerugian. Kepercayaan ini masih melekat di masyarakat pada umumnya bahwa besi tersebut mengandung kekuatan gaib ( ada penunggunya makhluk halus yang sering mengikuti besi). Sehingga keyakinan ini tidak terlepas dari memohon agar kekuatan yang ada tersebut dapat menjadi kekuatan positif dapat mempengaruhi jiwa pemakainya serta meminta ijin agar selalu di dalam keselamatan. Jika ini tidak dilakukan dengan tepung tawar, sebagian kepercayaan masyarakat akan mempengaruhi jiwa, kendaraan bisa menabrak atau ditabrak dan bahkan bisa hilang dicuri yang biasa diungkapkan dengan kata-kata "Sueh". Lafaz doa yang disebutkan tidak bisa sembarangan melalui tata cara tertentu.

Alat-alat yang digunakan dalam tepung tawar ialah tepung beras, beras kuning, daun juang-juang dengan batangnya diikat menjadi satu, dan berteh. Selanjutnya masing-masing dimasukkan ke dalam mangkok kecil yang berbeda dan mangkukmangkuk tersebut diletakkan ke atas talam kecil. Orang yang memercikan air pada prosesi acara dan benda atau barang adalah orang-orang yang dihormati atau dituakan dan dipandang seperti tokoh agama, tokoh masyarakat, dan tokoh adat.

Dalam pelaksanaannya tepung tawar dikenal 4 macam diantaranya yaitu tepung tawar mayit, tepung tawar peralatan, tepung tawar badan dan tepung tawar rumah. Dari keempat jenis tersebut mempunyai perbedaan dari segi alat-alat maupun bahanbahannya yang digunakan.

Tepung tawar mayat digunakan ketika keluarga yang meninggal setelah tiga hari dimakamkan, umumnya dilakukan sebagai pembersih peralatan yang dipakai mandi mayit, peralatan yang disimpan diluar rumah di tepung tawar yang disebut dengan acara Pesulli (pembersihan peralatan mayit) lalu telur ayam yang diletakkan pada tong tempat air memandikan mayit. Alat-alat 
tepung tawar mayit yang dipakai dilampas dengan daun ribu-ribu serta peralatan yang lainnya. Peralatan yang sudah bersih baru boleh dibawa masuk kedalam rumah yang sebelumnya disimpan di luar rumah. Telur yang disimpan pada tong dibuang segera dan tempat pemandian mayit ditaburi dengan abu dapur sebagai ungkapan bahwa di dalam kehidupan semua pasti mati dan yang telah terjadi menjadi pasrah laksana abu yang kembali ketempat asalnya. Dari prosesi tersebut mempunyai tujuan yang dikenal dengan Pesilli, agar ahli keluarga yang ditinggalkan senantiasa sabar menerima cobaan dari Allah. Dapat terhindar dari musibah dengan memohon agar dijauhkan dari segala musibah yang datang dengan mohon keselamatan, tidak hanya manusia dan juga peralatan yang telah dipakai dengan wujud terima kasih telah dipergunakan sebagai peralatan mandi.

Tepung tawar badan digunakan untuk anak kecil yang melaksanakan gunting rambut, pernikahan, dan dikhitan bagi lakilaki dan perempuan. Sasaran yang akan diberikan menurut tata cara yang berlaku, serta dilampas dengan memakai daun juangjuang maupun daun ribu-ribu yang telah di celupkan pada seperangkat peralatan tepung tawar. Bahan-bahannya terdiri dari, tepung beras, beras kuning, berteh daun juangjuang, daun gandarusa ,daun pacar, serta miyak bau (minyak Bugis). Minyak bau nantinya diolesi pada bagian tubuh tertentu dan bagi kaum wanita cukup dengan syarat tidak perlu menyentuh bagian tubuh (pusar). Adapun bagian-bagian yang dikenakan secara berurutan pada kening, bahu kanan,bahu kiri, tangan kanan, tangan kiri, kaki kanan, serta kaki kiri sementara paduan berteh dihamburkan pada kiri dan kanan tersebut. Ritual tepung tawar tidak bisa dikerjakan sembarangan karena menggunakan lafaz khusus yang tidak bisa diungkapkan disini, perlu diterima terlebih dahulu pada ahlinya

Dari rangkaian tersebut mempunyai fungsi sebagai rasa dan wujud syukur kepada Allah SWT serta harapan dan menolak bala' (musibah). Tak dilepaskan juga dari saling menghormati dan menghargai yang tua, mempererat tali silaturahmi, menjaga rasa solidaritas sesama di dalam kehidupan yang beragam dan terhindar dari malapetaka.

Kroeber dalam Zaenuddin (2013: 18) ialah keseluruhan realisasi, gerak, kebiasaan, tata cara, gagasan dan nilai-nilai yang dipelajari dan diwariskan dan perilaku yang ditimbulkannya. Dari pernyataan tersebut bahwa pola hidup masyarakat Melayu memiliki suatu kebiasaan salah satunya tepung tawar yang menjadi sebuah prosesi atau tata cara maupun alat-alat yang digunakan. Ada yang beranggapan asal muasal tradisi tepung tawar sebenarnya merupakan warisan dari budaya Hindu, Dengan datangnya Islam membawa perubahan dengan menghapus keyakinan animisme dan dinamisme.

Dari pemaparan tersebut maka peneliti mencoba membuat sebuah model rencana pelaksanaan pembelajaran (RPP) yang dikaitkan dengan kearifan lokal masyarakat melayu Pontianak yang disebut dengan RPP Berbasis Kearifan Lokal. Salah satu model RPP kearifan lokal berikut ini pada materi aqiqah dan tepung tawar badan pada gunting rambut anak.

\section{RENCANA PELAKSANAAN PEMBELAJARAN}

(RPP)

$\begin{array}{ll}\text { Satuan Pendidikan } & \text { : MA Al-Ikhlas } \\ \text { Mata Pelajaran } & \text { : Fiqih } \\ \text { Kelas } & \text { : X (Sepuluh) } \\ \text { Semester } & \text { : I (Ganjil) } \\ \text { Materi Pokok } & : \text { Aqiqah dan tepung tawar badan pada gunting rambut anak } \\ \text { Alokasi Waktu } & : 1 \times 45 \text { menit }\end{array}$

\section{A. Kompetensi Inti}


1. Menghargai dan menghayati ajaran agama yang dianutnya

2. Menghargai dan menghayati perilaku jujur, disiplin, tanggung jawab, peduli (toleransi, gotong royong), santun, percayadiri, dalam berinteraksi secara efektif dengan lingkungan sosial dan alam dalam jangkauan pergaulan dan keberadannya.

3. Menyajikan pengetahuan factual dan konseptual dalam bahasa yang jelas, sistematis, logis dan kritis, dalam karya yang estetis, dalam gerakan yang dalam tindakan yang mencerminkan perilaku anak beriman dan berakhlak mulia.

4. Mengolah, menyaji dan menalar dalam bentuk kongkret (menggunakan, mengurai, merangkai, memodifikasi, dan membuat) dan ranah abstrak (menulis, membaca, menghitung, menggambar, danmengarang) sesuai dengan yang dipelajari di sekolah dan sumber lain yang sama dalam sudut pandang/ teori.

\section{B. Kompetensi Dasar}

1.5 Menghayati nilai-nilai mulia dari syariat aqiqah dan tepung tawar badan pada gunting rambut anak

2.5 Membiasakan sikap peduli kepada orang lain sebagai implementasi dari nilai-nilai yang terdapat pada ibadah aqiqah dan tepung tawar badan pada gunting rambut anak

3.5 Menganalisis tata cara pelaksanaan aqiqah dan tepung tawar badan pada gunting rambut anak

4.5 Mendemonstrasikan pelaksanaan aqiqah sesuai syariat dan tepung tawar badan pada gunting rambut anak serta hikmahnya

\section{Indikator Pencapaian Kompetensi}

3.5.2 Menjelaskan tata cara pelaksanaan aqiqah dan tepung tawar badan pada gunting rambut anak

3.5.4 Menjelaskan hikmah aqiqah dan tepung tawar badan pada gunting rambut anak

\section{Tujuan Pembelajaran}

1. Siswa mampu menjelaskan tata cara pelaksanaan aqiqah dan tepung tawar badan pada gunting rambut anak dengan baik.

2. Dapat menjelaskan hikmah aqiqah dan tepung tawar badan pada gunting rambut anak dengan baik.

\section{E. Materi Pembelajaran}

Aqiqah dan tepung tawar badan pada gunting rambut.

\section{F. Strategi \& Metode Pembelajaran}

Strategi: The Power Of Two

Metode: ceramah, tanya jawab, diskusi

\section{G. Media Pembelajaran}

Power Point, infokus, buku teks, LKS

\section{H. Sumber Belajar}

Buku Paket, Buku LKS, Internet,handout, buku-bulu lainnya.

\section{Langkah-langkah Pembelajaran}

\begin{tabular}{|l|l|l|}
\hline No & Deskripsi Kegiatan Guru dan Siswa & Alokasi waktu \\
\hline 1 & $\begin{array}{l}\text { Pendahuluan/Kegiatan Awal } \\
\text { Orientasi : }\end{array}$ & 5 Menit \\
\hline
\end{tabular}




\begin{tabular}{|c|c|c|}
\hline & $\begin{array}{l}\text { Guru mengucapkan salam, meminta siswa berdo'a sebelum } \\
\text { pembelajaran, dan guru mengabsen kehadiran siswa. } \\
\text { Guru memberitahukan materi yang dipelajari hari ini tentang } \\
\text { aqiqah dan tepung tawar badan pada gunting rambut anak. } \\
\text { Apersepsi dan Pre Tes } \\
\text { Guru melakukan tanya jawab bersama siswa berkaitan dengan } \\
\text { materi yang sudah di pelajari selanjutnya mengaitkannya dengan } \\
\text { materi yang akan dipelajari. } \\
\text { Tujuan } \\
\text { Guru menyampaikan tujuan pembelajaran. } \\
\text { Motivasi } \\
\text { Guru mengajak siswa agar terlibat aktif dalam proses } \\
\text { pembelajaran. }\end{array}$ & \\
\hline 2 & $\begin{array}{l}\text { Kegiatan inti } \\
\text { a. Mengamati } \\
\text { Dapat ditunjukkan dengan aktivitas belajar seperti melihat, } \\
\text { membaca, mendengar, dan menyimak mengenai aqiqah dan } \\
\text { tepung tawar badan pada gunting rambut anak. } \\
\text { b.Menanya } \\
\text { Dapat dilakukan dengan mengajukan pertanyaan tentang } \\
\text { informasi yang tidak dipahami dari apa yang diamati atau } \\
\text { pertanyaan untuk mendapatkan informasi tambahan tentang apa } \\
\text { yang diamati mengenai aqiqah dan tepung tawar badan pada } \\
\text { gunting rambut anak. } \\
\text { c. Mengeksplorasi (Eksperimen/Mencoba) } \\
\text { Dapat dilakukan dengan cara membaca sumber lain selain buku } \\
\text { teks, mengamati objek/kejadian/pertunjukan, melakukan uji } \\
\text { coba, berdiskusi, mempraktekkan keterampilan dan lain } \\
\text { sebagainya mengenai aqiqah dan tepung tawar badan pada } \\
\text { gunting rambut anak. } \\
\text { d. Menalar (Mengasosiasi) } \\
\text { Dilakukan dengan cara mengolah informasi yang sudah } \\
\text { dikumpulkan. Pengolahan informasi dilakukan untuk } \\
\text { menemukan keterkaitan satu informasi dengan informasi lainnya, } \\
\text { menemukan pola dari keterkaitan informasi dan bahkan } \\
\text { mengambil berbagai kesimpulan pola yang ditemukan. } \\
\text { Pengolahan informasi dikumpulkan dari yang bersifat menambah } \\
\text { keluasan dan kedalaman sampai kepada pengolahan informasi } \\
\text { dikumpulkan dari yang bersifat menambah keluasan dan } \\
\text { kedalaman sampai kepada pengolahan informasi yang bersifat } \\
\text { mencari solusi dari berbagai sumber mengenai aqiqah dan tepung } \\
\text { tawar badan pada gunting rambut anak. } \\
\text { e. Mengkomunikasikan } \\
\text { Dilakukan dengan cara menyampaikan hasil pengamatan, } \\
\text { kesimpulan berdasarkan hasil analisis secara lisan, tulisan atau } \\
\text { media lainnya. Hasil tersebut disampaikan di kelas dan dinilai } \\
\text { oleh guru sebagai hasil belajar peserta didik atau kelompok } \\
\text { peserta didik mengenai aqiqah dan tepung tawar badan pada } \\
\text { gunting rambut anak. }\end{array}$ & 20 Menit \\
\hline
\end{tabular}




\section{J. Penilaian}

Penilaian terhadap proses dan hasil pembelajaran dilakukan oleh guru untuk mengukur tingkat pencapaian kompetensi siswa. Hasil penilaian digunakan sebagai bahan penyusunan laporan kemajuan hasil belajar dan memperbaiki proses pembelajaran.

\section{TUGAS}

Membaca handout yang telah dibagikan tentang materi aqiqah dan tepung tawar badan pada gunting rambut anak

\begin{tabular}{|c|c|c|c|c|c|c|c|}
\hline \multirow[t]{2}{*}{ No } & \multirow[t]{2}{*}{ Nama siswa } & \multicolumn{5}{|c|}{ Aspek Yang Diamati } & \multirow[t]{2}{*}{ Ket } \\
\hline & & 1 & 2 & 3 & 4 & 5 & \\
\hline 1 & Inaratushaleha & $\sqrt{ }$ & & & & & \\
\hline 2 & Siswanto & & & $\sqrt{ }$ & & & \\
\hline 3 & Fitri & $\sqrt{ }$ & & & & & \\
\hline 4 & Putri & & $\sqrt{ }$ & & & & \\
\hline & & & & & & & \\
\hline & & & & & & & \\
\hline
\end{tabular}

Aspek yang dinilai

1. Keaktifan

2. Kerjasama

3. Keseriusan

4. Keberanian berpendapat

5. Kemampuan berbahasa

Skor penilaian :

Nilai $=\quad$ Skor Perolehan $\times 100$

Skor maksimal

Kriteria Nilai

A $\quad=80-100$ kriteria Baik Sekali

$\mathrm{B} \quad=70-79$ kriteria Baik

$\mathrm{C}=60-69$ kriteria Cukup

$\mathrm{D} \quad=<60 \quad$ kriteria Kurang

\section{Tes Lisan}

\begin{tabular}{|l|l|l|}
\hline No. & \multicolumn{1}{|c|}{ Soal/jawaban } & Poin \\
\hline 1. & $\begin{array}{l}\text { Jelaskan pengertian aqiqah dan tepung tawar badan pada } \\
\text { gunting rambut anak? } \\
\text { Jawaban: }\end{array}$ & 50 \\
\hline $\mathbf{2}$ & $\begin{array}{l}\text { Jelaskan hikmah aqiqah dan tepung tawar badan pada gunting } \\
\text { rambut anak? } \\
\text { Jawaban: }\end{array}$ & 50 \\
\hline
\end{tabular}

\section{PENUTUP}

Berdasarkan pembahasan tersebuts ialah tepung tawar merupakan kebudayaan masyarakat Melayu Pontianak yang diintegrasikan dengan pembelajaran Pendidikan Agama Islam (PAI) dalam suatu rancangan yang dinamakan rencana pelaksanaan pembelajaran (RPP) berbasis kearifan lokal.

Hal ini membantu pelestarian budaya lokal setempat dengan mengenalkan dan 
mengajak generasi muda peduli akan pentingnya kearifan lokal yang mengandung nilai-nilai pendidikan Islam.

\section{DAFTAR PUSTAKA}

Aslan. 2017. Nilai-Nilai Kearifan Lokal Dalam Budaya Pantang Larang Suku Melayu Sambas dalam Jurnal Ilmu Ushuluddin Vol.16.(1). Hal. 1120.

Atem. 2017. The Meaning of the Actions in the Tradition of Makan Bersaprah at the Wedding of Sambas Malay dalam Jurnal International Journal of Multidisciplinary Approach and Studies Vol.4. (5). Hal. 13-23.

Basir, A. 2013. Nilai Pendidikan Islam Dalam Budaya Tenongan Nyadran Suran Di Dusun Giyanti Wonosobo dalam Jurnal Kependidikan AlQalam Vol.9. Hal. 69-78.

Creswell, J.W. 2014. Penelitian Kualitatif dan Desain Riset: Memilih Di Antara Lima Pendekatan. Yogyakarta: Pustaka Pelajar.

Demina. 2013. Membumikan Nilai Budaya Lokal Dalam Membangun Karakter Bangsa.

Jurnal Ta'dib Vol.16.(1). Hal. 1-13.

Frimayanti, A.I. Implementasi Pendidikan Nilai Dalam Pendidikan Agama Islam dalam Jurnal Al-Tadzkiyyah Vol. 8.(2). Hal. 227-247.

Koentjaraningrat. 1990. Pengantar Ilmu Antropologi. Jakarta: Rhineka Cipta.

Masita. 2012. Pendidikan Karakter Berbasis Budaya Lokal Pada masyarakat Muslim dalam Jurnal Studi
Masyarakat Islam Vol.15.(2). Hal. 302-320.

Mafirja, S.dkk. 2018. Rangkaian Pelaksanaan "Edet Mungerje" Berdasarkan Kearifan Lokal (Local Wisdom) Suku Gayo Takengon Aceh Tengah dalam Prosiding Online Seminar Nasional dan Workshop Bimbingan dan Konseling 2018. Hal. 102-108.

Majid, A. 2016. Strategi Pembelajaran. Bandung: PT. Remaja Rosdakarya.

Priyatna, M. 2016. Pendidikan Karater Berbasisi Kearifan Lokal dalam Jurnal Edukasi Islami Vol. 5. Hal. 1311-1336.

Samad,S.A.A. 2017. Agama, Budaya dan Perubahan Sosial Perspektif

Pendidikan Islam di Aceh dalam Jurnal Mudarrisuna Vol. 7.(1). Hal. 28.

Wahab. 2015. Sapa And Base Communication Of Sambas Society: A Case Of Malay-Madurese PostConflict 1999-2014 dalam Jurnal International Journal Of Scientific \& Technology Research Vol. 4.(2). Hal. 253-256. 2013. Kapita Selekta Pendidikan Islam. Pontianak: STAIN Pontianak Press.

Yusriadi. 2017. Berandep, Kearifan Lokal Masyarakat Melayu Di Dabong, Kubu Raya Kalimantan Barat dalam Jurnal Khatulistiwa Vol. 1. (1).

Zaenuddin. 2013. Pengantar Antropologi. Pontianak: STAIN Pontianak Press 
Jurnal Tarbiyah: Jurnal Ilmiah Kependidikan

Vol. 8 No. 1 Januari - Juni 2019 (53-62) 